\title{
Response of phytoplankton assemblages isolated for short periods of time in a hyper-eutrophic reservoir (Lake Chivero, Zimbabwe)
}

\author{
Lindah Mhlanga ${ }^{1 *}$, Wilson Mhlanga ${ }^{2}$ and Pamela Tendaupenyu ${ }^{1}$ \\ 'University of Zimbabwe, Department of Biological Sciences, P.O. Box MP 167, Mt. Pleasant, Harare, Zimbabwe \\ ${ }^{2}$ Bindura University of Science Education, Department of Environmental Science, Private Bag 1020, Bindura, Zimbabwe
}

\begin{abstract}
The response of phytoplankton assemblages isolated in enclosures for short periods of time was examined in hypereutrophic Lake Chivero (Harare, Zimbabwe), to determine the factors that influenced the structure of the phytoplankton community, after noticing a marked decline in the dominance of Microcystis aeruginosa in recent years. The phytoplankton assemblage in the lake during summer, winter and the end of winter was dominated by Cryptomonas sp. and Cyclotella sp., with an average relative abundance of $>95 \%$, based on phytoplankton biomass estimations. Isolation in summer resulted in the exclusion of Cyclotella sp., a decline of Cryptomonas sp. and an increase in M. aeruginosa and Anabaena sp. In winter, when M. aeruginosa was absent in the inoculum, isolation resulted in an increase in Cryptomonas sp. biomass and a decline of Cyclotella sp. At the end of winter Cryptomonas sp. initially increased but later declined following the increase in chlorophytes. The non-equilibrium state in Lake Chivero caused pioneer species to dominate rather than $\mathrm{M}$. aeruginosa.
\end{abstract}

Keywords: Microcystis aeruginosa, non-equilibrium state, pioneer species, turbulence

\section{INTRODUCTION}

Eutrophication is the predominant factor that has influenced phytoplankton dynamics in Lake Chivero (Harare, Zimbabwe) since its formation (Marshall, 2005), resulting in the perpetual dominance of cyanobacteria, mainly Microcystis aeruginosa Kütz. (Munro, 1966; Marshall, 1997). However, from February 2003 to December 2006 a marked decline in the dominance of M. aeruginosa was observed (Mhlanga et al., 2006). This decline in the dominance of M. aeruginosa, a specialist algal species according to Reynolds classification (1996), was noticed despite the high nutrient levels in the lake. Dominance by specialists indicates a state of equilibrium. Phytoplankton succession proceeds with decreasing species diversity towards a climax or equilibrium stage (Reynolds, 1996). We postulate that the decline of specialists in Lake Chivero could indicate that the system was in a state of instability. Although nutrient levels were above the limiting levels for cyanobacteria (Mhlanga et al., 2006), specialists were not dominant in Lake Chivero; instead, conditions were favourable for Cryptomonas sp. and Cyclotella $\mathrm{sp}$. indicating that there might have been at least one factor overriding the effect of nutrients in determining the lack of M. aeruginosa dominance.

Christian et al. (1986) reckoned that turbulence is an important factor since an unstable water column is a major deterrent to the development of cyanobacterial blooms (Reynolds and Walsby, 1975). In Lake Chivero there could have been a 'continuous disturbance', an event that persistently interrupted the progression of phytoplankton succession to equilibrium, by constantly resetting the succession to an earlier stage wherein pioneer species dominated (Connell, 1978;

\footnotetext{
To whom all correspondence should be addressed.

iㅛ +263 772236 525; Fax: +2634480303;

e-mail: 1mhlanga67@gmail.com or lmhlanga@science.uz.ac.zw Received 23 January 2013; accepted in revised form 17 December 2013.
}

Sommer et al., 1993). When turbulence was low, algal cells would migrate to the surface, but sudden turbulence would prevent the build-up of a high biomass (Mhlanga et al., 2006). We therefore hypothesised that continuously turbid conditions, indicative of turbulence, were disrupting the build-up of $M$. aeruginosa biomass in the euphotic zone and could be influencing the species dominance pattern. To test this hypothesis we assessed the variation in composition and biomass of isolated phytoplankton assemblages in enclosures.

When observations are made to evaluate how environmental variability influences assemblage structure, Dos Santos and Calijuri (1997) recommend that the scale of observation should fit as closely as possible to the scale of organism response or generation time. The average generation time for phytoplankton is between 1 and 2 days (Dos Santos and Calijuri, 1997). It has also been observed that changes in the stability of the water column, at intervals of about 10 days, are responsible for changes in the composition and maintenance of species diversity, and that the biomass and taxonomic composition of the phytoplankton assemblage can change in a few days in response to changes in the mixing layer (Reynolds and Reynolds, 1985; Harris, 1986). A period of 9 to 11 days was therefore considered as an appropriate duration to represent the response time while a sampling interval of 2 days represented the generation time. We assumed that nutrients would not decline to limiting levels in the enclosures within the period of 11 days, allowing us to make inferences about the effect of forcing factors other than nutrients on the phytoplankton assemblage.

\section{MATERIALS AND METHODS}

\section{Study area}

This study was carried out in Lake Chivero, a man-made lake that was created in 1956 and is located about $37 \mathrm{~km}$ southwest of the city of Harare, Zimbabwe (Fig. 1). Lake Chivero 


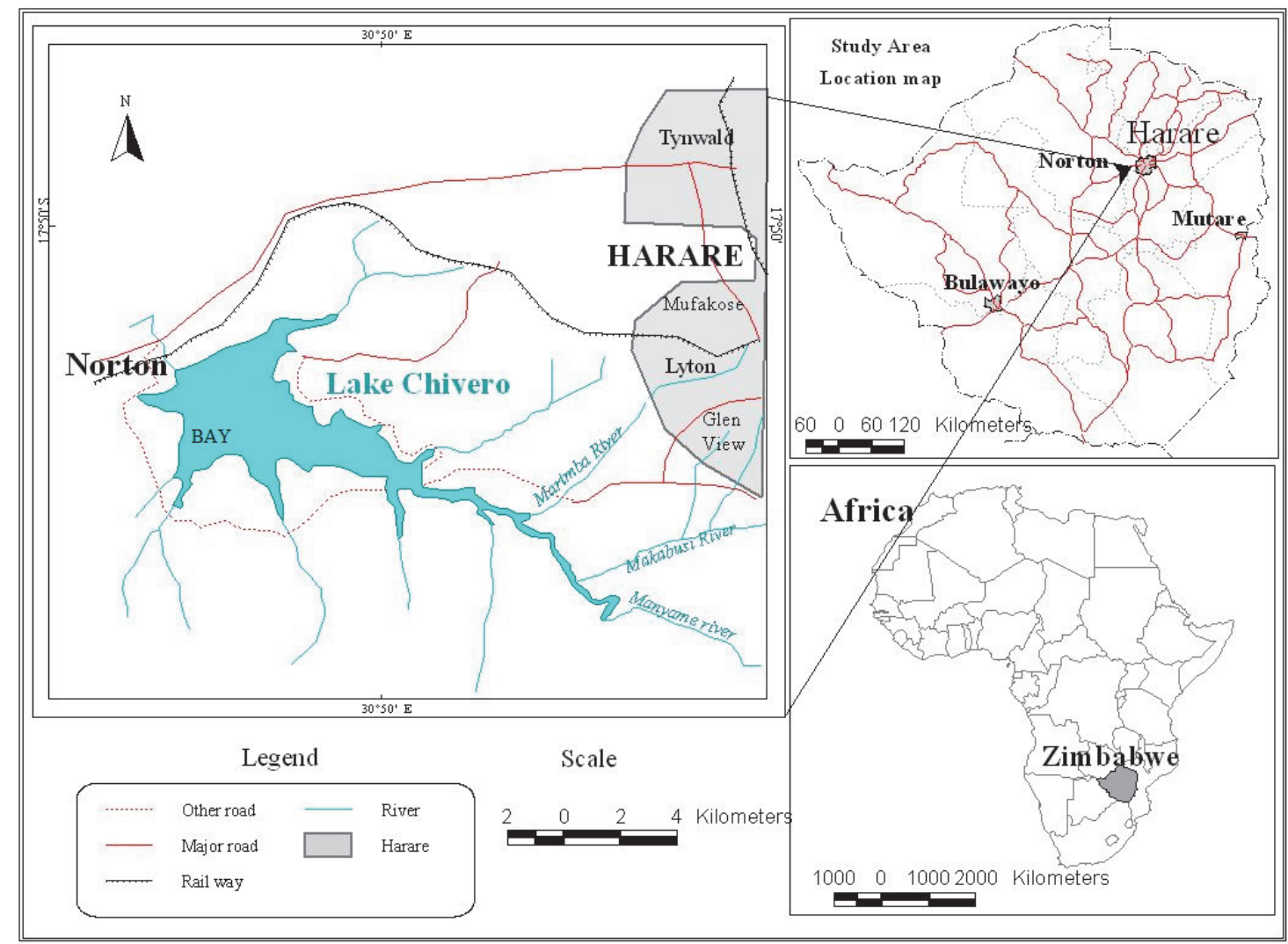

Figure 1

Map of Lake Chivero showing the location of the bay where the study was carried out

experiences 2 major seasons: namely, a hot, wet summer (from November to April) and a cool, dry winter (from May to August) with a hot, dry transitional minor season (from September to October). Sampling during this study was carried out on 3 occasions representing summer (21 February to 2 March 2005), winter (21 to 31 May 2005) and the end of winter (15 to 25 August 2005). Temperature, $\mathrm{pH}$ and dissolved oxygen were measured using WTW field meters (Geotech Environmental Equipment, Inc. Denver, Colarado, USA). Phytoplankton samples were preserved in Lugol's iodine solution.

\section{Lake sampling}

Water was collected from the euphotic zone in a bay within which enclosure experiments were undertaken (Fig. 1). Three replicate samples were collected from the lake every second day at the same time as the enclosures were sampled. A Ruttner sampler was used to collect water within $1 \mathrm{~m}$ depth.

\section{Enclosure sampling}

The experimental enclosures were made of $0.2-\mathrm{mm}$ reinforced polyethylene. Each enclosure had a capacity of $1 \mathrm{~m}^{3}(1 \times 1 \mathrm{x}$ $1 \mathrm{~m})$, was closed at the bottom and open to the atmosphere. A special support system enabled the enclosures to float, with the rim above the water surface. The algal assemblage was isolated into in-situ enclosures. A water pump was used to pump lake water and ambient algal assemblage into 3 replicate enclosures on each occasion. The enclosures were incubated for a maximum of 11 days and a minimum of 9 days in a bay in Lake Chivero where the maximum depth was about $3 \mathrm{~m}$ (Fig. 1). Samples from the three replicate enclosures were obtained every second day for analysis. Prior to sample collection the water within the enclosures was thoroughly mixed with a stirrer and then collected with a Ruttner sampler. Water was collected from the enclosures between 09:00 and 11:00 on each sampling occasion.

\section{Laboratory analysis}

Nutrient analyses were carried out following the methods in Golterman et al. (1978).

Utermöhl's sedimentation method was used to enumerate the phytoplankton (Utermöhl, 1958; Cronberg, 1982). Phytoplankton species were identified using charts and keys from literature (Komárek, 2005). The functional group of phytoplankton were classified according to the ecological concept of adaptive strategies (Reynolds 1988). Reynolds (1988) classified the phytoplankton species into 3 basic adaptive strategies based on their susceptibility to habitat disturbance, stress and utilisation of limited resources: $\mathrm{C}$ (competitors, colonistinvasives), $\mathrm{S}$ (stress-tolerants) and $\mathrm{R}$ (disturbance-tolerant ruderals). C-strategists which can reproduce rapidly dominate when intensity of stress and disturbance is low in environments saturated with nutrients and light (Soylu and Gönülol, 2010). R-strategists can tolerate turbulent transportation and light gradients in environments with great vertical mixing, while S-strategists develop in situations of low disturbance (Soylu and Gönülol, 2010) 

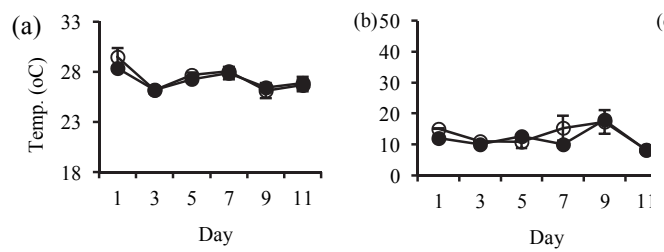

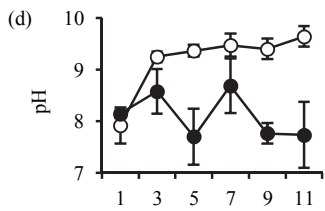

Day

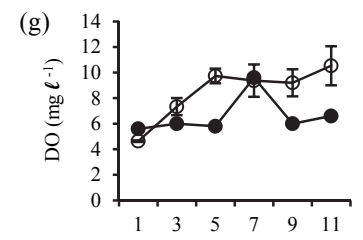

Day

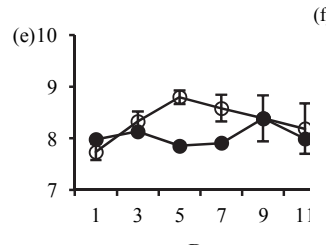

Day

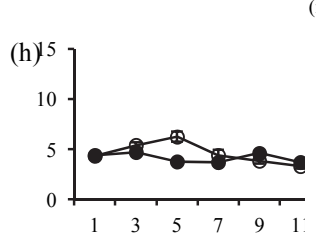

Day

Figure 2

Variations in temperature (temp.), $\mathrm{pH}$ and dissolved oxygen concentration (DO) in the enclosures (o) and the lake $(\bullet)$ over short periods $[(a),(d)$ and $(g)=$ summer; (b), (e) and (h) = winter; $(c)$, $(f)$ and (i)= end of winter]
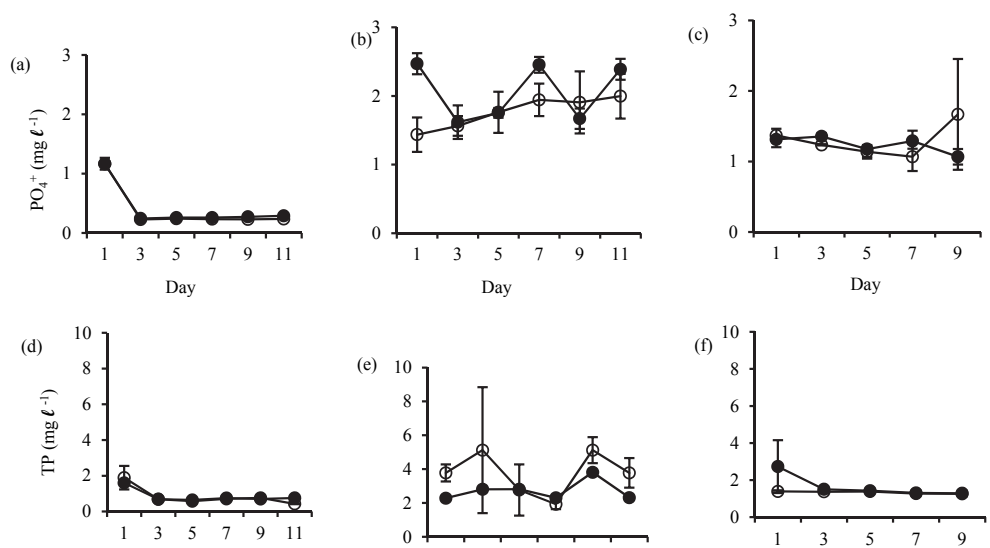

Day
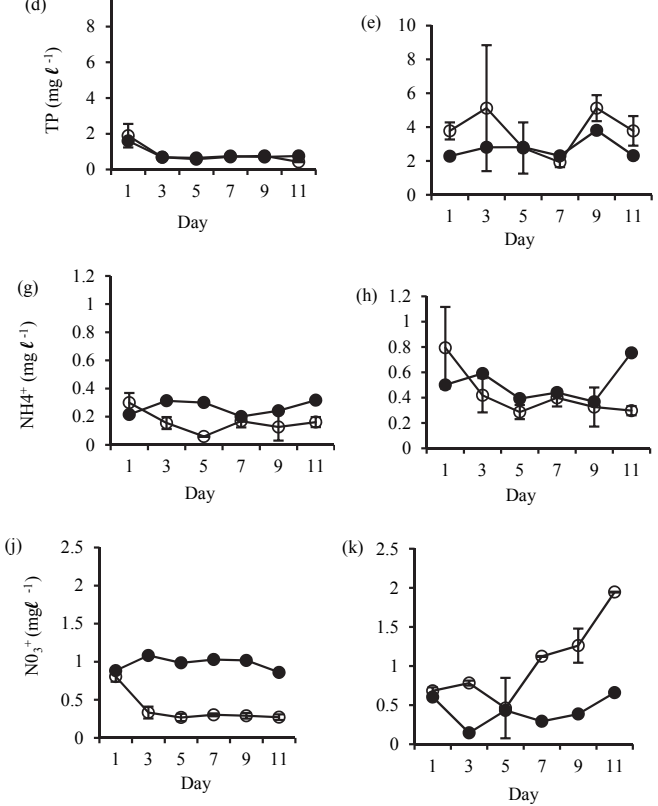

Figure 3

Variations of orthophosphate $\left(\mathrm{PO}_{4}^{+}\right)$, total phosphorus (TP), ammonium $\left(\mathrm{NH}_{4}^{+}\right)$, and nitrate $\left(\mathrm{NO}_{3}^{+}\right)$concentrations in the enclosures (o) and the lake (•) over short periods $[(a),(d),(g)$ and $(j)=$ summer; $(b),(e),(h)$ and $(k)=$ winter; $(c),(f),(i)$ and (I) $=$ end of winter]

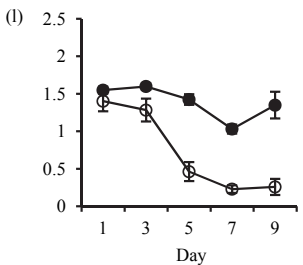

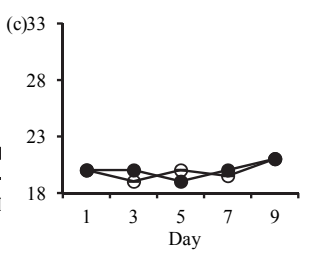

\section{Data analysis}

Differences between the lake and the enclosures were tested with Repeated Measures Analysis of Variance (ANOVA) using Stastica 7.

\section{RESULTS}

\section{Physico-chemical characteristics}

Isolation in enclosures on all occasions resulted in a significant increase in $\mathrm{pH}$ and dissolved oxygen concentration (Fig. 2). Temperature was not significantly different in the lake and in the enclosures during summer (Fig. 2a: $\mathrm{F}(5,12)=1.4 p>0.05)$ and at the end of winter (Fig. $2 \mathrm{c}$ : $\mathrm{F}(1,10)=0.3 p>0.05)$. However, the enclosure temperature was significantly lower than lake temperature during winter (Fig. 2b: $\mathrm{F}(5,12)=4.3 p<0.05)$.

Isolation in enclosures resulted in a decrease in nutrient levels, except during winter when an increase in nitrate and orthophosphate concentrations occurred (Fig. 3). Although nutrient concentrations generally declined in the enclosures they remained above the limiting levels for phytoplankton growth.

Orthophosphate concentration increased in the enclosures during winter from $1.3 \mathrm{mg} \cdot \ell^{-1}$ on Day 1 to $1.7 \mathrm{mg} \cdot \ell^{-1}$ on Day 11. Orthophosphate concentrations in the lake and the enclosures were not significantly different in summer (Fig. 3a: F $(5,12)=1.6 p>0.05)$ and at the end of winter (Fig. 3c: F $(4,10)=1.7 p$ $>0.05$ ), while in winter the enclosure orthophosphate concentration was significantly lower than lake concentration (Fig. 3b: $\mathrm{F}(5,12)=4.5 p<0.05)$.

Total phosphorus was not significantly different between the enclosure and the lake in summer (Fig. 3d: $\mathrm{F}(5,12)=0.5 p>0.05$ ), winter (Fig. 3e: $\mathrm{F}$ $(5,12)=1.1 p>0.05)$ and at the end of winter (Fig. 3f: $\mathrm{F}(4,10)=2.6 p>0.05)$.

Ammonium concentration was significantly higher in the lake than in the enclosures in summer (Fig. 3g: $\mathrm{F}(5,12)=17.7 p<0.05)$ and winter (Fig. 3h: $F(5,12)=6.8 p<0.05)$, while at the end of winter there was no significant difference (Fig. 3i: $\mathrm{F}(4,10)$ $=2.2 p>0.05$ ).

In winter, nitrate concentrations increased in the enclosures from a concentration of $0.4 \mathrm{mg} \cdot \ell^{-1}$ at Day 5 to $1.9 \mathrm{mg} \cdot \ell^{-1}$ at Day 11 . Nitrate concentrations were significantly higher in the lake in summer (Fig. 3j: $\mathrm{F}(5,12)=75 p<0.05)$, winter (Fig. $3 \mathrm{k}: \mathrm{F}(5,12)=$ $20.2 p<0.05$ ) and at the end of winter (Fig. 31: F $(4,10)=14.6 p<0.05)$.

\section{Phytoplankton assemblage and biomass}

The phytoplankton assemblages in the lake during all three periods were dominated by Cryptomonas sp. with an average relative abundance of $>65 \%$, and which together with Cyclotella sp. comprised $>90 \%$ of the biomass. The functional groups of dominant phytoplankton species observed in Lake Chivero during the study periods is shown in Table 1. The R-strategists dominated. 


\begin{tabular}{|c|c|}
\hline \multicolumn{2}{|c|}{$\begin{array}{c}\text { TABLE 1 } \\
\begin{array}{c}\text { Functional classification of dominant phytoplankton species } \\
\text { observed in Lake Chivero }\end{array}\end{array}$} \\
\hline Species & Classification \\
\hline $\begin{array}{l}\text { Pediastrum sp. } \\
\text { Coelastrum sp. } \\
\text { Scenedesmus } \mathrm{sp} .\end{array}$ & $\begin{array}{l}\text { C- Strategists (competitors, } \\
\text { invasives) }\end{array}$ \\
\hline $\begin{array}{l}\text { Microcystis aeruginosa } \\
\text { Anabaena sp. } \\
\text { Anabaenopsis tanganyikae } \\
\text { Trachelomonas sp. }\end{array}$ & S-Strategists (stress-tolerant) \\
\hline $\begin{array}{l}\text { Cryptomonas sp. } \\
\text { Cyclotella sp. } \\
\text { Alaucoseira granulata }\end{array}$ & $\begin{array}{l}\text { R-Strategists (disturbance- } \\
\text { tolerant ruderals) }\end{array}$ \\
\hline
\end{tabular}
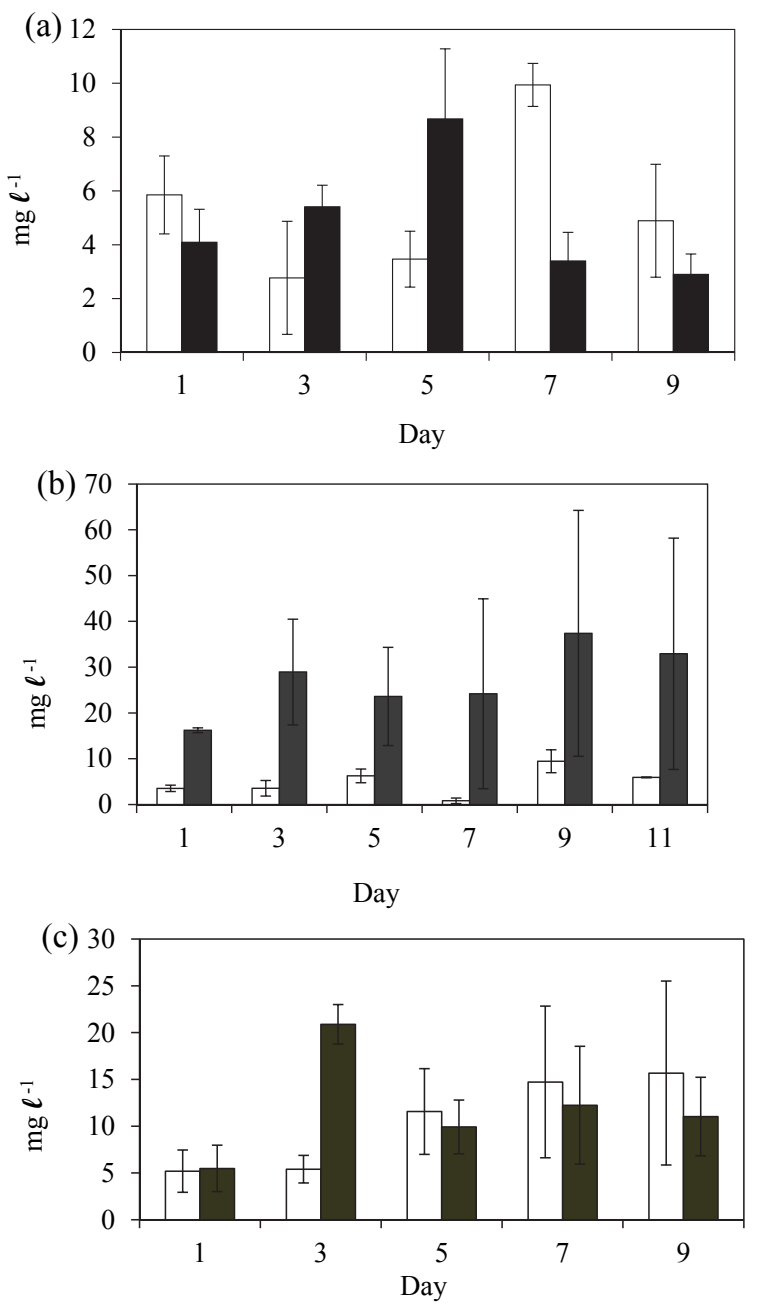

Figure 4

Variations in total biomass of phytoplankton in the enclosures (घ) and the lake ( $\square$ ) during (a) summer (b) winter and (c) end of winter

\section{Summer period}

During summer, total biomass increased between Day 1 and 5 after isolation (Fig. 4a). This was due to an increase in the population of Cryptomonas sp. However, the biomass decreased from Day 7 when a switch from Cryptomonas/ Cyclotella co-dominance to dominance by $M$. aeruginosa occurred. The total biomass was not significantly different (a) Lake - summer

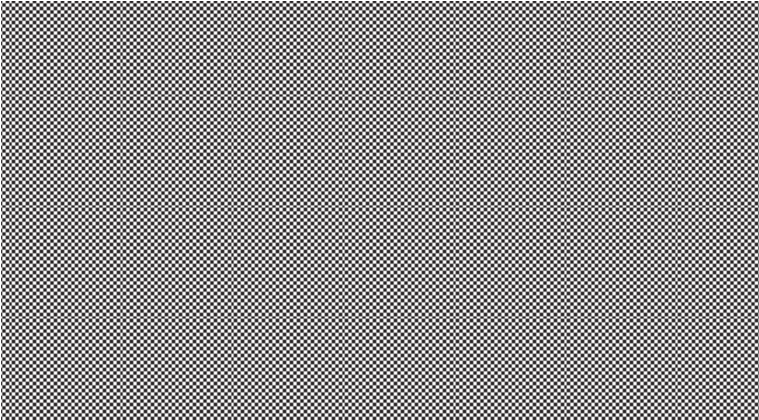

(b) Enclosure - summer

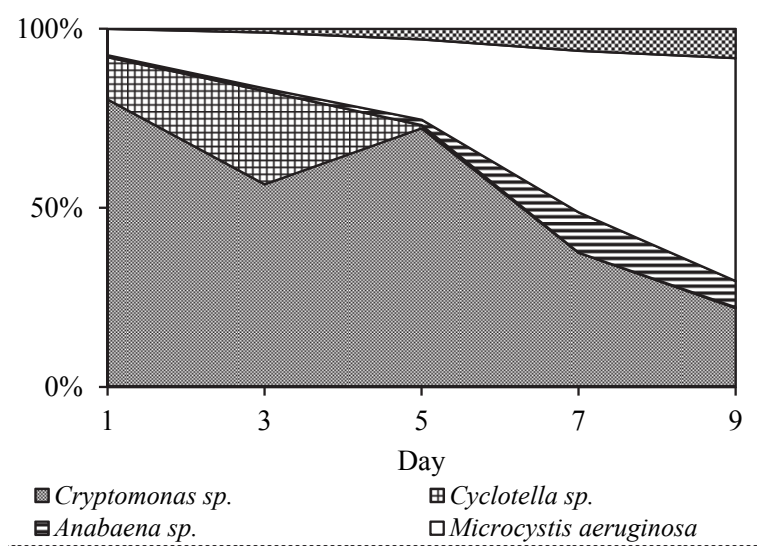

Figure 5

The relative abundances of the most abundant phytoplankton species based on phytoplankton biomass estimations in the lake and the enclosures during summer

between the lake and the enclosures over the summer time (Fig. 4a: F $(5,9)=0.5 p>0.05)$.

The variation in the relative abundances of the dominant species in the lake and in the enclosures during summer is shown in Fig. 5. During summer the phytoplankton assemblage in the lake was comprised of Cryptomonas sp. with a relative biomass $>65 \%$, and which together with Cyclotella sp. comprised $>90 \%$ of the total biomass (Fig. 5a). Two cyanobacterial species, M. aeruginosa and Anabaena sp., contributed $<10 \%$ of the total biomass in the lake. Rare species included Pediastrum duplex and Trachelomonas sp. In the enclosures Cryptomonas sp. and Cyclotella sp. co-dominated with a relative biomass contribution of $>90 \%$, while cyanobacteria comprised only $8 \%$ (Fig. 5b). All species, but especially Cyclotella sp., increased in biomass by Day 3 of isolation. Cyclotella sp. was absent from the enclosures after Day 5. Microcystis aeruginosa continued to increase from Day 3 and had assumed $69 \%$ of the total biomass at Day 9 (Fig. 5b). Cryptomonas sp. remained dominant up to Day 5, after which it declined to $22 \%$ of the relative biomass by Day 9 . Isolation in summer resulted in the exclusion of Cyclotella sp., a decline of Cryptomonas sp. and an increase in M. aeruginosa and Anabaena sp.

\section{Winter period}

The biomass of Cryptomonas sp. in the enclosures during winter increased markedly (Fig. 4b). The mean enclosure total biomass was significantly higher than the mean lake total biomass 
(a) Lake

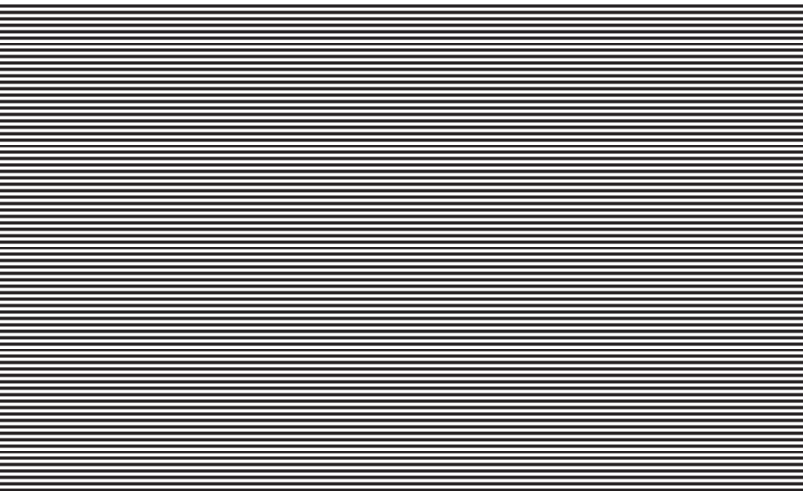

(b) Enclosure

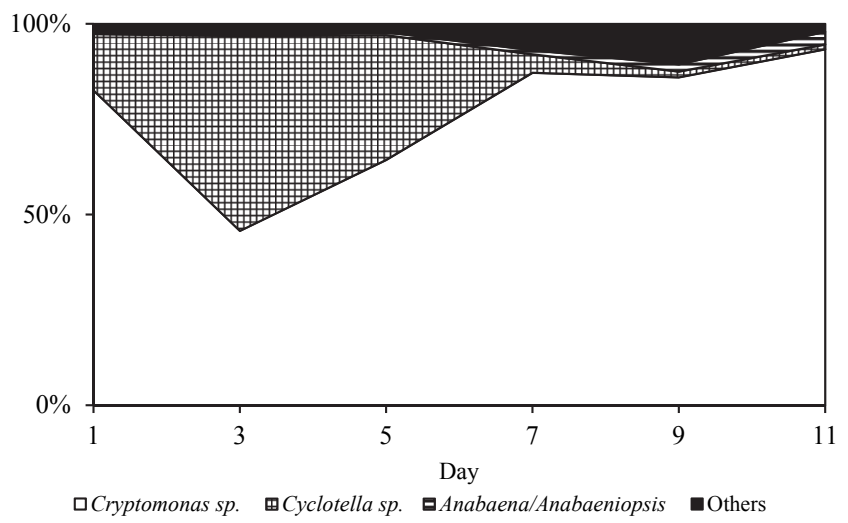

Figure 6

The relative abundances of the most abundant phytoplankton species based on phytoplankton biomass estimations in the lake and the enclosures during winter

$(\mathrm{F}(1,12)=26.2 p<0.005)$. However, variability over time was not significantly different $(\mathrm{F}(5,12)=0.3 p>0.05)$, indicated by the high degree of overlap of the 0.95 confidence intervals. Generally total biomass was higher in winter than in summer and at the end of winter.

During winter Cryptomonas sp. and Cylotella sp. were dominant in the lake comprising $>95 \%$ of the total biomass, with cyanobacteria comprising Anabaena sp. and Anabaenopsis tanganyikae (G.S. West) Wolosz. Et Mill. making up $<2 \%$ of the biomass (Fig. 6a). Chlorophytes (Pediastrum duplex and Coelastrum spp.) and euglenophytes were rare. Cryptomonas sp. and Cyclotella sp. co-dominated in the enclosures with a relative biomass of $>90 \%$ until Day 5 (Fig. 6b). As Cryptomonas sp. biomass continued to increase in the enclosures Cylotella sp. declined. Cryptomonas sp. had assumed $93 \%$ of the total biomass by Day 9. Anabaena sp., A. tanganyikae and chlorophytes also increased slightly in the enclosures. Isolation in winter resulted in an increase in biomass of Cryptomonas sp. and a decline in Cyclotella sp.

\section{End of winter period}

Total biomass in the lake increased gradually over the period of 9 days at the end of winter (Fig. 4c). Maximum biomass in the enclosures was attained on Day 3 (Fig. 4c). The mean lake biomass was not significantly different from the mean enclosure biomass (Fig. $4 \mathrm{c}: \mathrm{F}(1,10)=0.9 p>0.05$ ) although both the (a) Lake

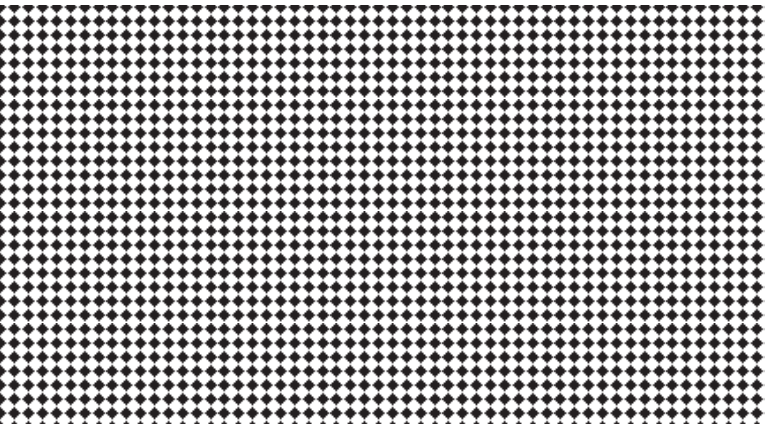

(b) Enclosure

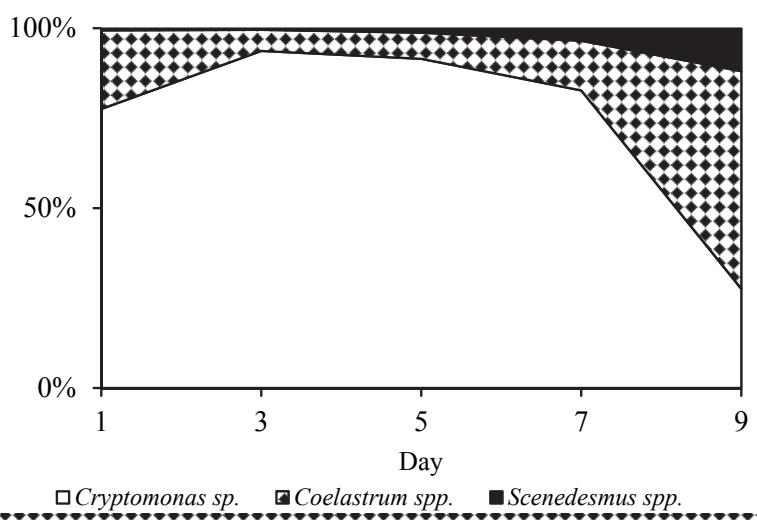

Figure 7

The relative abundances of the most abundant phytoplankton species based on phytoplankton biomass estimations in the lake and the enclosures at the end of winter

enclosure and lake biomasses varied significantly with time (Fig. 4c: F $(4,10)=5.7 p<0.05$ )

The phytoplankton assemblage in the lake at the end of winter was comprised of Cryptomonas sp. and chlorophytes (3 Coelastrum species and 3 Scenedesmus species) (Fig. 7). Cryptomonas sp. was dominant in the lake comprising $>88 \%$ of the total biomass throughout the period (Fig. 7a). In the enclosures the phytoplankton assemblage was dominated by Cryptomonas sp. until Day 7 when a switch occurred to dominance by Coelastrum spp. (Fig. 7b). Isolation at the end of winter resulted in an initial increase in the biomass of Cryptomonas sp. that later declined following a switch to dominance by chlorophytes.

\section{DISCUSSION}

Phytoplankton biomass was enhanced by isolation. Although the temporal change was not significant, an increase in biomass in the enclosures was apparent between Day 1 and Day 5. The higher $\mathrm{pH}$ and dissolved oxygen in the enclosures indicated that primary productivity was higher in the enclosures than in the lake. This indicated that small-scale random perturbations could be important in regulating phytoplankton biomass in Lake Chivero. The marked fluctuations of phytoplankton biomass in the lake are an indication of the effect of physical perturbations. According to Haffner and McNeely (1989), small-scale perturbations can shift a phytoplankton assemblage from being regulated by buoyancy or nutrient concentration to being regulated by turbulence or temperature. The increase 
in biomass just by isolation shows that turbulence could be an important factor since nutrients were either lower in the enclosures or not different between the enclosures and the lake. The assumption is that turbulence was reduced in the enclosures when lake water was isolated. It was also possible that light conditions in the enclosures would be better than in the lake and therefore would have enhanced phytoplankton primary production, whereas in the lake the algae were circulated down into dim light several times during the day (Knapp et al., 2003).

It has been established that 1-to-13-day physical perturbations can be major constraints that regulate dynamics of phytoplankton assemblages (Millet and Cecchi, 1992). Drastic perturbations by wind at 2-week intervals induced a recurring re-initialisation of succession in Thau lagoon, such that succession never continued beyond dominance by opportunist species (Millet and Cecchi, 1992). In Lake Chivero physical disturbances could be limiting the development of algal succession from ruderal plants and cryptophytes to specialists because, according to Padisák et al. (1988), a minimum calm period of 5-7 days is necessary for a shift from ruderal plants to specialists.

The effect of physical disturbances was illustrated by the pattern of species replacement after isolating different phytoplankton assemblages during the summer, winter and end of winter seasons. In summer, isolation of a phytoplankton assemblage comprising Cryptomonas sp. and Cyclotella sp. as well as specialists (M. aeruginosa and Anabaena sp.) resulted in the gradual competitive decline of Cryptomonas sp. and Cyclotella sp. after 7-9 days. After 9 days M. aeruginosa and Anabaena sp. dominated, and Cyclotella sp. was excluded, while Cryptomonas sp. had declined.

In winter, when the isolated phytoplankton assemblage did not include significant biomass of M. aeruginosa, Cryptomonas sp. remained dominant, although the build-up in biomass of Cryptomonas sp. after 7 days resulted in a decline in Cyclotella sp. abundance. At the end of winter the isolation of a phytoplankton assemblage that was comprised of Cryptomonas sp. and chlorophytes resulted in a decrease in Cryptomonas sp. as the biomass of Coelastrum spp. increased. Comparatively, in the lake both Cyclotella sp. and Cryptomonas sp. dominated during summer and winter while Cryptomonas sp. and Coelastrum spp. dominated at the end of winter.

Physical mixing and turbulence can play major roles in preventing one species from completely dominating another (Harris, 1986), which may partly explain the decline in dominance by $M$. aeruginosa in Lake Chivero during the study period. The phytoplankton assemblage may have been frequently adjusting to persistent turbulence, resulting in $M$. aeruginosa being out-competed because mixing counteracts the near-surface accumulations of buoyant $M$. aeruginosa, thereby forcing competition for light with non-buoyant eukaryotic taxa.

Wind fluctuations strongly influence the physical perturbations of the water column on a daily scale, which in turn strongly influences phytoplankton dynamics. Since the influence of wind was not measured directly, isolation of 3 distinct phytoplankton assemblages in enclosures indirectly showed that water column perturbations could account for part of the observed natural variability in phytoplankton dynamics in Lake Chivero.

Nutrients were highest in the lake during winter, probably arising from overturn (Marshall, 1997). This could have provided ideal conditions for Cryptomonas sp. to increase in biomass. Elsewhere, cryptophytes have been observed to establish maximum populations during or immediately after a redistribution of nutrients in the water column caused by turbulent mixing (Klaveness, 1988; Pautova et al., 1989; Istavánovics et al., 1994). Their marked increase was attributed to their small size and high area/volume ratio that enabled them to attain high rates of growth and respiration (Dos Santos and Calijuri, 1998).

In Lake Chivero, Cryptomonas sp. is now a dominant species (Mhlanga et al., 2006), as demonstrated by its dominance during the summer, winter and end of winter seasons in this study. Reynolds (1996) proposed a sequential dominance in phytoplankton succession of (i) R-strategist ruderal plants dominating during periods of mixing, (ii) C-strategist growth specialists dominating at the beginning of stratification and (iii) S-strategist specialists dominating at the end of the stratification period and at the end of the succession. This pattern was not exhibited in Lake Chivero; instead cryptophytes and C-strategists (baccillariophytes) comprised the algal assemblage during summer, winter and end of winter. This shows that perturbations in aquatic ecosystems can change the expected trajectory of algal succession resulting in other functional groups of algae adapted to those perturbations dominating (Reynolds, 1993).

Although temperature influences the physical structure of ecosystems (Dos Santos and Calijuri, 1998), it is unlikely to have influenced the dominance of cyanobacteria. Microcystis aeruginosa only occurred during summer in the lake.

Microcystis aeruginosa was not limited by nutrients since nutrient levels were high during the winter. Other species dominated instead. The conditions were not favourable for M. aeruginosa, a specialist and an indicator of structural stability in lakes (Reynolds, 1988). Its increase in the enclosures during summer showed that it favours a physically stable environment.

Except for nitrate, which increased during winter and which coincided with an increase in the abundance of 2 nitrogen-fixing cyanobacterial species, Anabaena sp. and Anabaenopsis tanganyikae, the other nutrients declined in the enclosures as they were utilised by phytoplankton and bacteria. It is not apparent why there was a slight increase in Anabaena sp. and A. tanganyikae in the enclosures during winter compared to the other periods. The two species were also observed in the lake, but in the enclosures there was an increase in their populations at the end of the experiment. The increase in these species in the enclosures seemed to be related to the physical stability provided within the enclosures, which contrasted with the constantly perturbed state in the lake. The increase in nitrate could be evidence of nitrogen fixation or of oxygenation that caused a shift from $\mathrm{NH}_{4}$ to $\mathrm{NO}_{3}$, which is inferred by the increase in nitrate concentrations in the lake from Day 7 , although the increase in nitrate lagged behind the levels in the enclosures, probably because it was constantly dispersed by mixing in the lake. The decline in ammonium and nitrate concentrations in the enclosures showed that both nutrients were used as sources of nitrogen by phytoplankton and bacteria. An increase in orthophosphate concentration in the enclosures during winter could have resulted from contamination of the enclosures by bird faecal matter. Many birds were present on Lake Chivero at that time.

The lake phytoplankton assemblage was similar in all three seasons with respect to dominance by Cryptomonas sp., except for the presence of $M$. aeruginosa in summer, Anabaena sp. and Anabaenopsis tanganyikae in winter and a slight increase of chlorophytes at the end of winter. The community in the lake typified a state of non-equilibrium with the dominance 
of species that grow rapidly (R-selective or C-strategists). Cryptomonas sp., which occurred together with Cyclotella sp., has been reported to survive in a large variety of environmental conditions, either during the mixing period or during stratification (Reynolds, 1982; 1984; 1996).

The dominance of Cryptomonas sp. in Lake Chivero confirmed that its survival strategy was intermediate between those of the growth strategists (C) and the species that were tolerant of disturbances (ruderal plants), as observed by Dos Santos and Calijuri (1998). It successfully managed to outcompete M. aeruginosa in Lake Chivero. Cyclotella sp. was also dominant, especially in winter, although it sometimes occurred with Alaucoseira granulata (E.) Simons. Diatoms are growth strategists and ruderal plants, and dominate during periods of circulation with high availability of nutrients, especially nitrogen, and good light conditions (Sommer, 1988). In winter when Cyclotella sp. was abundant, the lake was isothermal, indicating that mixing had occurred (Mhlanga et al., 2006).

During this study A. granulata was not present in the lake although it was recorded between 2003 and 2004 (Mhlanga et al., 2006). The shift from dominance by A. granulata to Cyclotella sp. showed that diatoms can exhibit a wide spectrum of responses and survival strategies in relation to nutrient availability, light and competition. Cyclotella sp. seems to have adapted more successively to the existing conditions than $A$. granulata. The growth of diatoms is mainly related to the ratio of silica to phosphorus and availability of light (Reynolds, 1984; Dos Santos and Calijuri, 1998); phosphorus concentrations and light availability were high in Lake Chivero in winter (silica was not measured).

During winter Cyclotella sp. comprised over $80 \%$ of the total biomass and assumed absolute dominance. Favourable conditions in winter included high availability of nutrients as a result of lake circulation, good light conditions since the lake was clear, and high concentrations of nitrate, conditions which are preferred by diatoms (Sommer, 1988).

It appeared that Cyclotella sp. and Cryptomonas sp. benefited from the decline of $M$. aeruginosa during the study period. They successively occupied niches that were freed by $M$. aeruginosa because of their morphological structures and reproductive processes. As observed in the enclosures during summer, the excessive growth of $M$. aeruginosa completely suppressed these two species, confirming the observation by Murphy and Lean (1976) that during blue-green algal blooms other algae can be completely suppressed.

Conditions in the lake were not favourable for the dominance of $M$. aeruginosa but were favourable for Cyclotella sp. and Cryptomonas sp., which is typical of the initial phases of succession. It has been observed in subtropical environments that $M$. aeruginosa is numerically superior during periods of summer stratification (Reynolds et al., 1981), while during mixing the alga remains in the sediments (Bell and Ahlgren, 1987). Although it occurred in summer during this study it was not numerically superior to other taxa. Cryptophytes dominated, showing the dominance of a community in a state of non-equilibrium. According to Reynolds (1984), ruderal plants favour unstable environmental conditions with strong water mixing and high availability of phosphorus and nitrogen resources.

This study showed that turbulence from wind mixing prevented the accumulation of high algal biomasses in Lake Chivero, including that of cyanobacteria. Generally, seasonal variations in phytoplankton dynamics have been linked to nutrient fluctuations, which were presumed to be the principal forcing function in Lake Chivero. This study, however, showed that events with shorter periods, such as weeks or days, might be relevant to the dynamics of the reservoir (Fonseca, 1997). The decline of $M$. aeruginosa during the study period indicated the importance of the role played by allogenic factors in regulating the composition and abundance of cryptomonads over short-term time scales (Haffner and McNeely, 1989).

An increase in stability in the enclosures led to an increase in chlorophyll $a$ concentrations and in the biomass of all species, including cyanobacteria, within the enclosures. Confinement of the phytoplankton assemblage enhanced cyanobacterial dominance, but when $M$. aeruginosa was absent isolation perpetuated the dominance of Cryptomonas sp. The non-equilibrium state in Lake Chivero caused by turbulence presented an ideal niche for species with higher growth rates. It appears that constant physical disturbances might be regulating the phytoplankton assemblage leading to an increase in species richness and diversity in the algal assemblage of Lake Chivero rather than the dominance of $M$. aeruginosa.

\section{ACKNOWLEDGEMENTS}

This study was supported by a research grant received from Water Research Fund for Southern Africa and technical support from the University of Zimbabwe's Lake Kariba Research Station.

\section{REFERENCES}

BELL RT and AHLGREN I (1987) Thymidine incorporation and microbial respiration in the surface sediment of a hypertrophic lake. Limnol. Oceanogr. 32 476-482.

CHRISTIAN RR, BRYANT WL and STANLEY DW (1986) The relationship between river flow and Microcystis aeruginosa blooms in the Neuse River, North Carolina, Water Resources Research Institute Report. 223. North Carolina State University, Raleigh.

CONNELL JH (1978) Diversity in tropical rainforests and coral reefs. Science 199 1302-1310.

CRONBERG G (1982) Phytoplankton changes in Lake Trummen induced by restoration. Folia Limnol. Scand. 18 1-119.

DOS SANTOS ACA and CALIJURI MC (1997) Phytoplankton communities over a short period of time, in the Barra Bonita Reservoir (State of São Paulo, Brazil): microcosm experiments. Verh. Internat. Verein Limnol. 26 468-471.

DOS SANTOS ACA and CALIJURI MC (1998) Survival strategies of some species of the phytoplankton community in the Barra Bonita Reservoir (São Paulo, Brazil). Hydrobiologia 367 139-152.

FONSECA CP (1997) Plankton community dynamics over short periods at Jacaré-Pepira Reservoir, State of São Paulo, Brazil. Verh. Internat. Verein. Theor. Angew. Limnol. $26472-477$.

GOLTERMAN HL, CLYMO RS and OHASTAD AM (1978) Methods for Chemical and Physical Analysis of Freshwater. IBP Handbook No. 8 ( $2^{\text {nd }}$ edn.). Blackwell Scientific Publications, London. 214 pp.

HAFFNER GD and McNEELY R (1989) Community structure in epilimnetic and metalimnetic phytoplankton assemblages. Hydrobiologia 182 59-71.

HARRIS GP (1986) Phytoplankton Ecology: Structure, Function and Fluctuation. Chapman Hall, London. 384 pp.

STAVÁNOVICS V, PADISÁK J, PETTERSON K and PIERSON DC (1994) Growth and phosphorus uptake of summer phytoplankton in Lake Erken, Sweden. J. Plankton Res. 16 1167-1196.

KOMÁREK J (2005) Cyanoprokaryota. $2^{\text {nd }}$ Part: Oscillatoriales. Elsevier $\mathrm{GmbH}$, München. 757 pp.

KLAVENESS D (1988) Ecology of the Cryptomonadida: a first review. In: Sandgren SD (ed.) Growth and Reproductive Strategies of Freshwater Phytoplankton. Cambridge University Press, Cambridge. 105-133.

KNAPP CW, DENOYELLES JRF, GRAHAM DW and BERGIN S (2003) Physical and chemical conditions surrounding the diurnal 
vertical migration of Cryptomonas spp. (Cryptophyceae) in a seasonally stratified mid-western reservoir (USA). J. Phycol. 39 855-861.

MARSHALL BE (1997) Lake Chivero after forty years: the impact of eutrophication. In: Moyo NAG (ed.) Lake Chivero: A Polluted Lake. University of Zimbabwe Publications, Harare, Zimbabwe. 1-12.

MARSHALL BE (2005) The impact of eutrophication on Lake Chivero, Zimbabwe: A tropical African reservoir. In: Reddy MV (ed.) Restoration and Management of Tropical Eutrophic Lakes. Science Publishers, Plymouth, United Kingdom. 165-186.

MHLANGA L, DAY J, CRONBERG G, CHIMBARI M, SIZIBA N and ANNADOTTER H (2006) Cyanobacteria and cyanotoxins in the source water from Lake Chivero, Harare, Zimbabwe and the presence of cyanotoxins in drinking water. Afr. J. Aquat. Sci. 31 165-174.

MILLET B and CECCHI P (1992) Wind-induced hydrodynamic control of phytoplankton biomass in a lagoon ecosystem. Limnol. Oceanogr. 37 140-146.

MUNRO JL (1966) A limnological survey of Lake Mcllwaine, Rhodesia. Hydrobiologia 28 281-308.

MURPHY TP and LEAN DRS (1976) Blue-green algae: their excretion of selective chelators enables them to dominate other algae. Science 192 900-902.

PADISÁK J, TÓTH G AND RAJCZY M (1988) The role of storms in the summer succession of the phytoplankton community in a shallow lake (Lake Balaton, Hungary). J. Plankton Res. 10 249-265.

PAUTOVA LA, PAUTOVA VN and SILKIN VA (1989) Phytoplankton succession in a waterbody. Symp. Biol. Hung. 38 117-121.

REYNOLDS CS and WALSBY AE (1975) Water blooms. Biol. Rev. 50 437-481.

REYNOLDS CS and REYNOLDS JB (1985) The atypical seasonality of phytoplankton in Crose Mere, 1972: an independent test of the hypothesis that variability in the physical environment regulates community dynamics and structure. Br. Phycol. 20 227-242.

REYNOLDS CS (1982) Phytoplankton periodicity: its motivation, mechanisms and manipulation. Ann. Rep. Freshwater Biol. Assoc. $5060-75$.

REYNOLDS CS (1984) Phytoplankton periodicity: the interactions of form, function and environment variability. Freshwater Biol. 14 111-142.

REYNOLDS CS (1988) Functional morphology and adaptive strategies of freshwater phytoplankton. In: Sandgren CD (ed.) Growth and Reproductive Strategies of Freshwater Phytoplankton. Cambridge University Press, Cambridge. 388-433.

REYNOLDS CS (1993) Scales of disturbance and their role in plankton ecology. Hydrobiologia 249 157-171.

REYNOLDS CS (1996) The plant life of the pelagic. Verh. Internat. Theor. Angew. Limnol. 26 97-113.

REYNOLDS CS, JAWORSKI GHM, CMIECH HA and LEEDALE GF (1981) On the annual cycle of the blue-green algae Microcystis aeruginosa Kütz. emed. Elenkin. Philos. Trans. R. Soc. London [Biol.] 293 419-478.

SOMMER U, PADISAK J, REYNOLDS CS and JUHASZ-NAGY P (1993) Hutchnson's heritage: the diversity-disturbance relationship in phytoplankton. Hydrobiologia 249 1-8.

SOMMER U (1988) Growth and survival strategies of plankton succession. In: Sommer U (ed.) Plankton Ecology - Succession in Plankton Communities. Springer Series in Contemporary Biosciences, Berlin. 57-106.

SOYLU EN and GÖNÜLOL A (2010) Functional classification and composition of phytoplankton in Liman Lake. Turkish J. Fish. Aquat. Sci. 10 53-60.

UTERMÖHL H (1958) Zur Vervollkommung der quantitativen. Phytoplankton methodik. Mitt. Int. Verein. Theor. Angew. Limnol. 91-38. 